\title{
KAJIAN POTENSI KETERSEDIAAN AIR PADA EMBUNG RANTAU BARU GUNA KEBUTUHAN AIR IRIGASI DI SUB DAERAH ALIRAN SUNGAI TAPIN
}

\author{
Akhmad Gazali \\ Dosen Prodi (S-1)Teknik Sipil, Fakultas Teknik, Uniska MAB \\ Jalan Adhyaksa No. 2, Banjarmasin, Kalimantan Selatan 70123 \\ E-mail: akhmadgazali51@gmail.com/HP.+6285249529517
}

\begin{abstract}
ABSTRAK
Air merupakan sumberdaya alam yang sangat penting untuk kelangsungan hidup dan kegiatan komersial seperti pertanian, air minum, industri dan usaha lainnya. Perkembangan suatu daerah akan menyebabkan kebutuhan air terus meningkat seiring dengan lajunya pertumbuhan penduduk dan taraf hidupnya. Kecenderungan yang sering terjadi adalah adanya ketidakseimbangan antara ketersediaan air dan kebutuhan air sehingga menimbulkan terjadinya krisis air. Tujuan yang ingin dicapai dalam tinjauan ini adalah untuk mengetahui jumlah ketersediaan air Embung Rantau Baru sepanjang tahun.
\end{abstract}

Dalam penulisan ini dilakukan analisis hidrologi yang terdiri dari analisis evapotranspirasi, analisis ketersediaan air dan analisis debit andalan di Embung Rantau Baru. Metode yang dipakai untuk menganalisis ketersediaan air adalah dengan metode NRECA, dimana metode ini mensimulasikan keseimbangan air bulanan pada suatu daerah pengaliran sungai tertentu yang ditunjukkan untuk menghitung total limpasan dengan menggunakan hujan bulanan, evapotranspirasi dan kelembaban tanah.

Berdasarkan hasil analisis dapat disimpulkan bahwa ketersediaan air Sungai Salak pada kondisi debit andalan (Q80\%), debit paling rendah pada bulan Mei, Juni, Juli, Agustus dan September sebesar 0,000 $\mathrm{m} 3 /$ detik (volume air 0,000 m3) dan paling tinggi 0,287 m3/detik (volume air 0,767 juta $\mathrm{m} 3$ ) pada bulan Januari. Ketersediaan air di Embung Rantau Baru totalnya sebesar 2,712 juta m3/tahun.

Kata Kunci: Ketersediaan Air, Debit, Embung Rantau Baru.

\section{ABSTACT}

Water is a natural resource that is very important for survival and commercial activities such as agriculture, drinking water, industry and other businesses. The development of an area will cause water demand to continue to increase along with the rate of population growth and standard of living. The tendency that often occurs is that there is an imbalance between water availability and water demand, causing a water crisis. The aim to be achieved in this review is to find out the amount of water available at Rantau Baru Basin throughout the year.

In this paper hydrological analysis is carried out which consists of evapotranspiration analysis, water availability analysis and mainstay discharge analysis in Rantau Baru Basin. The method used to analyze water availability is the NRECA method, where this method simulates the monthly water balance in a 
particular river drainage area which is shown to calculate total runoff using monthly rainfall, evapotranspiration and soil moisture.

Based on the results of the analysis, it can be concluded that the availability of Salak River water in the mainstay discharge conditions (Q80\%), the lowest discharge in May, June, July, August and September is 0,000 m3/second (water volume 0,000 m3) and the highest is 0,287 m3/seconds (volume of water 0.767 million m3) in January. The availability of water in Rantau Baru Basin totals 2.712 million m3/year.

Keywords: Availability of Water, Debit, Rantau Baru Basin.

\section{PENDAHULUAN}

Secara ideal, sebuah kota seharusnya dapat berfungsi dengan baik sebagai salah satu titik awal dari tumbuh, berkembang, dan meningkatnya kehidupan sosial, ekonomi dan masyarakat. Pertumbuhan, perkembangan dan peningkatan ini tidak hanya terjadi di kota tersebut tetapi juga menyebar ke kawasankawasan lain yang berada dalam wilayah pengaruhnya. Agar kota dapat berfungsi dengan baik, pertumbuhan dan perkembangannya perlu direkayasa, direncanakan, diarahkan dan dikendalikan. Namun, pada kenyataannya sering kali pertumbuhan dan perkembangan kota kurang terarah dan kurang terkendali. Akibatnya timbul berbagai permasalahan kota yang besar dan kompleks dengan segala konsekuensinya. Kondisi yang demikian nampaknya juga sudah terjadi di kota Rantau, ibukota kabupaten Tapin.

Dilihat dari sisi planologis dan manajemen perkotaan, pertumbuhan dan perkembangan kota Rantau selama ini terlihat kurang terarah dan terkendali. Hal ini tercermin dari kepadatan bangunan yang relatif tinggi, pertumbuhan kota yang seporadis dan menyebar, struktur kota yang tidak jelas dan belum terpola, kualitas visual kota yang relatif rendah dan berbagai permasalahan kota.

Dengan kondisi itu, nampaknya sulit untuk merubah kota Rantau yang ada sekarang menjadi sebuah kota yang berkualitas dan secara optimal dapat berperan dalam mendorong pertumbuhan ekonomi wilayah. Penerapan program peremajaan kota tentunya akan membutuhkan biaya ekonomi dan sosial yang tinggi, sementara hasilnya tidak akan optimal.

Situasi dan kondisi kota Rantau seperti yang digambarkan di atas menginspirasi Pemerintah Kabupaten Tapin untuk membangun kota Rantau menjadi sebuah kota yang berkualitas. Strategi yang terbaik adalah mewujudkan sebuah kawasan baru, yaitu kawasan Rantau Baru dalam konsep kota baru di dalam kota (new town in town).

Dalam Rencana Tata Bangunan dan Lingkungan (RBTL), salah satu rencana konsep kawasan Rantau Baru adalah konsep Kota Hijau (Green City). Dalam konsep tersebut tertuang rencana pendekatan konsep hijau biru (green blue plan) dalam kawasan perencanaan. Hal ini bertujuan untuk mengoptimalisasikan antara rencana hijau kawasan (vegetasi landscape) dan rencana biru kawasan pada area tepian sungai dengan cara kelayakan lahan dan membuat danau buatan tengah kota sehingga memberi kesan teduh, asri di dalam kawasan maupun di sepanjang jalan utama kota juga untuk memperkuat image sebagai kota Rantau sebagai kota bernuansa taman yang hijau. 
Berdasarkan hasil penelitian yang dilakukan oleh Tim Hidrologi AMDAL pada tahun 2008, fungsi danau buatan ini pada dasarnya sebagai tempat rekreasi dan kawasan hijau, namun pada saat musim kemarau diharapkan bisa menjadi tempat penampungan air untuk kebutuhan lahan sawah seluas $20 \mathrm{Ha}$ dan kebutuhan air di Mesjid Dulang yang terletak di hilir embung. Dalam penelitian ini, danau buatan tersebut diberi nama Embung Rantau Baru.

Permasalahan dimulai dengan asumsi bahwa ketika tahap pembuatan embung selesai dilaksanakan sesuai RTBL Rantau Baru, ketersediaan sumberdaya air dapat dipertahankan dengan tindakan-tindakan teknis dan manajemen, agar seluruh fungsi-fungsi embung yang dikehendaki dapat terlaksana dan diperlukan studi neraca air.

Berlatar belakang hal tersebut di atas, maka rumusan masalah penelitian ini adalah Bagaimana ketersediaan air yang ada di Embung Rantau Baru? Adapun tujuan penelitian ini adalah Mengetahui bagaimana ketersediaan air yang ada di Embung Rantau Baru. Untuk menghindari meluasnya lingkup penelitian ini dan memudahkan penyelesaian penelitian, serta konsentrasi studi yang terarah pada tujuan yang ingin dicapai, maka diperlukan batasan pada lingkup penelitian yang dilakukan, yaitu:

a. Daerah yang akan dilakukan penelitian adalah Embung Rantau Baru berada pada Sub Daerah Aliran Sungai Tapin, tepatnya pada alur Sungai Salak.

b. Penelitian dibatasi pada analisa ketersediaan air di Embung Rantau Baru, sedangkan analisa banjir tidak dikaji.

c. Pengolahan data yang meliputi: pengolahan data hidrologi, pengalihragaman hujan menjadi aliran dengan menggunakan model NRECA.

\section{Definisi dan Manfaat Embung}

Embung atau tandon air merupakan waduk berukuran mikro (small farm reservoir) yang dibangun untuk menampung kelebihan air hujan dan aliran permukaan di musim hujan. Air yang ditampung tersebut selanjutnya digunakan sebagai sumber irigasi suplementer untuk budidaya komoditas pertanian bernilai ekonomi tinggi (high added value crops) di musim kemarau atau di saat curah hujan tidak memenuhi kebutuhan irigasi.

Besarnya kapasitas tampungan suatu waduk atau embung yang direncanakan pada suatu regim sungai agar dapat memenuhi kebutuhan fungsionalnya tergantung dari 3 faktor berikut:

a. Variasi aliran sungai;

b. Besarnya kebutuhan air dan

c. Reliabilitas dari waduk/ embung.

Tampungan embung direncanakan memiliki luas \pm 20 ribu $\mathrm{m} 2(100 \mathrm{~m}$ x $200 \mathrm{~m})$ dengan ketinggian ratarata muka air dari dasar embung $3 \mathrm{~m}$. Tinggi jagaan banjir di tetapkan sebesar $1 \mathrm{~m}$. Untuk lebih jelas dapat dilihat pada Gambar 1 berikut ini. 


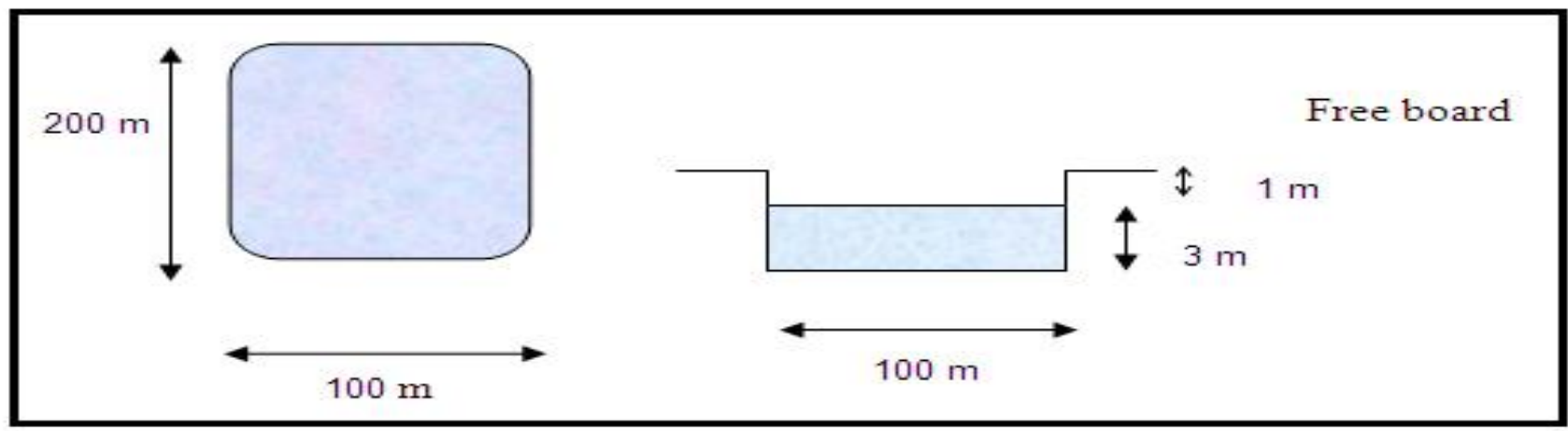

Gambar 1. Idealisasi Denah Embung dan Potongan

Sumber : RTBL Kawasan Rantau Baru

\section{Evapotranspirasi}

Evapotranspirasi (ET) adalah jumlah air total yang dikembalikan lagi ke atmosfer dari permukaan tanah, badan air, dan vegetasi oleh adanya pengaruh faktor-faktor iklim dan fisiologis vegetasi. Evapotranspirasi (ET) merupakan gabungan antara proses-proses evaporasi, intersepsi dan transpirasi. Evaporasi adalah proses penguapan, yaitu perubahan dari zat cair menjadi uap air atau gas dari semua bentuk permukaan kecuali vegetasi. Sedang transpirasi adalah perjalanan air dalam jaringan vegetasi (proses fisiologis) dari akar tanaman ke permukaan daun dan akhirnya menguap ke atmosfer. Intersepsi adalah penguapan dari permukaan vegetasi ketika berlangsung hujan. Besarnya laju transpirasi kurang lebih sama dengan laju evaporasi apabila pori-pori daun terbuka. Proses pembukaan pori-pori daun tampaknya dikendalikan oleh besarnya pembukaan diameter pori-pori daun. Ketika pori-pori daun menutup, proses transpirasi tetap berlangsung tetapi dengan laju yang sangat lambat (Wanielista dalam Riady, 1990).

Dalam studi ini digunakan metode Penman Modifikasi sebagai pendekatan untuk mencari harga evapotranspirasi, karena dalam metode ini digunakan data klimatologi yang lebih lengkap bila dibandingkan dengan kedua metode lainnya. Bentuk persamaan Penman yang telah dimodifikasi adalah:

$$
\text { Eto }=C \cdot[W \cdot R n+(1-W) \cdot F(U) \cdot(e a-e d)]
$$

Dimana:

Eto = evapotransporasi tetapan $(\mathrm{mm} / \mathrm{hari})$,

$C=$ faktor penyesuaian yang tergantung pada kecepatan angin siang hari, kelembaban udara relatif (RH) maksimum, perbandingan kecepatan angin siang dan malam hari,

$W \quad$ = faktor bobot yang tergantung pada temperatur dan ketinggian,

$R n=$ radiasi netto ekuifalen dengan evaporasi dalam $\mathrm{mm} / \mathrm{hari}$,

$F(U)=$ faktor bobot yang tergantung pada temperatur dan ketinggian,

$e a=$ tekanan uap air jenuh (mbar),

ed = tekanan uap air nyata (mbar).

\section{Ketersediaan Air}

Ketersediaan air yang merupakan bagian dari fenomena alam, sering sulit untuk diatur dan diprediksi dengan akurat. Hal ini karena ketersediaan air mengandung unsur variabilitas ruang (spatial variability) dan variabilitas waktu (temporal variability) yang sangat tinggi. Oleh karena itu, analisis kuantitatif dan 
kualitatif harus dilakukan secermat mungkin agar dapat dihasilkan informasi yang akurat untuk perencanaan dan pengelolaan sumberdaya air.

Untuk analisis ketersediaan air permukaan, yang akan digunakan sebagai acuan adalah debit andalan (dependable flow). Yang paling berperan dalam studi ketersediaan air permukaan adalah data rekaman debit aliran sungai. Rekaman tersebut harus berkesinambungan dalam periode waktu yang dapat digunakan untuk pelaksanaan proyek penyediaan air. Apabila penyadapan air akan dilakukan dari sungai yang masih alami, maka diperlukan rekaman data dari periode-periode aliran rendah yang kristis yang cukup panjang, sehingga keandalan pasok air dapat diketahui.

\section{Model NRECA}

Salah satu model yang dipakai dalam menghitung ketersediaan air adalah Metode NRECA (National Rural Electrical Cooperation Agency) yang dikembangkan oleh Norman H. Crawford (USA) pada tahun 1985, yang merupakan penyederhanaan dari Standford watershed model IV (SWM) yang memiliki beberapa parameter. Metode NRECA mensimulasikan kesetimbangan air bulanan pada suatu daerah tangkapan yang ditujukan untuk menghitung total run off dari nilai curah hujan bulanan, evapotranspirasi, kelembaban tanah dan ketersediaan air tanah. Model kesetimbangan air Metode NRECA didasarkan pada proses kesetimbangan air secara umum yakni hujan yang jatuh di atas permukaan tanah dan tumbuhan penutup lahan sebagian akan menguap, sebagian akan menjadi aliran permukaan dan sebagian lagi akan meresap masuk kedalam tanah. Infiltrasi air akan menjenuhkan tanah permukaan dan kemudian air akan merambat menjadi perkolasi dan keluar menuju sungai sebagai aliran dasar (base flow). Perbedaan Metode NRECA dengan model kesetimbangan air yang lain seperti Metode F.J. Mock terletak pada jumlah parameter yang digunakan.

Model ini digunakan untuk menghitung debit bulanan dari curah hujan bulanan berdasarkan keseimbangtan air di DAS. Konsep metode NRECA memerlukan input utama data hujan dan evapotranspirasi actual yang diilustrasikan pada Gambar 2.5. Kandungan air dalam tanah dihitung setiap bulan dan merupakan fungsi dari evapotrasnpirasi aktual dan curah hujan. Evapotrasnpirasi aktual dihitung dari evapotrasnpirasi potensial dan hujan dengan bantuan persamaan empiris (Trenggono dalam Gomeks, 2007). Model ini menggunakan dua parameter utama yaitu PSUB yang menggambarkan bagian kelebihan air hujan yang masuk ke dalam tampungan air tanah dan GWF yang mencerminkan bagian dari tampungan air tanah yang mengkontribusi aliran air sungai. Selain dari tampungan air tanah, aliran air di sungai sebagian besar dari kelebihan kelengasan tanah sebesar (1-PSUB). Dalam analisis ketersediaan air, metode perhitungan yang dilakukan untuk menghitung debit bulanan yang terjadi menggunakan data hujan bulanan dan evapotranspirasi. Persamaan dasar kesetimbangan air yang digunakan:

$$
R O=P-A E+\Delta S
$$

Dimana:

$R O=$ Keseimbangan air $(\mathrm{mm})$,

$P=$ Presipitasi (hujan rata-rata di DAS) $(\mathrm{mm})$,

$A E=$ Evapotranspirasi actual (penguapan aktual) $(\mathrm{mm})$,

$\Delta S=$ Perubahan tampungan. (mm). 




Gambar 2. Diagram Model Hujan Limpasan Metode NRECA

Sumber: Pedoman Kriteria Desain Embung Kecil

\section{METODE PENELITIAN}

\section{Materi Penelitian}

Ruang lingkup materi penelitian diarahkan pada tahapan-tahapan analisis untuk mencapai tujuan penelitian, yaitu:

1. Kajian terhadap karakeristik fisik dasar Embung Rantau Baru

Kajian ini diarahkan untuk mengetahui kondisi potensi ketersediaan sumberdaya air (water availability) di Embung Rantau Baru.

2. Kajian arahan pengelolaan sumberdaya air di lokasi penelitian

Berdasarkan hasil kajian sebelumnya, maka pada kajian ini dilakukan perumusan pola pengelolaan sumberdaya air dengan mempertimbangkan kondisi keseimbangan air alami.

\section{Pendekatan Penelitian}

Berdasarkan UU No.7 Tahun 2004 tentang Sumberdaya Air pasal 12 ayat 1 dan 2 disebutkan bahwa pengelolaan air permukaan melalui dasar wilayah DAS dan pengelolaan air tanah harus berdasarkan cekungan air tanah. Dalam penelitian ini, satuan pengamatan yang digunakan dalam bentuk morfologis berupa DAS tepatnya Sub DAS Tapin. Beberapa asumsi dasar yang digunakan dalam penelitian ini adalah:

1. Perhitungan ketersediaan sumberdaya air permukaan dilakukan dengan menggunakan pendekatan matematis metoda hidrometeorologi (pendekatan Water Balance versi NRECA). Oleh karenanya hasil yang didapatkan merupakan nilai hasil pendekatan matematis dan bukan nilai aktual.

2. Perhitungan potensi air permukaan dilakukan dengan menggunakan pendekatan batas wilayah DAS yang ada, dalam hal ini Sub DAS Tapin, dengan asumsi bahwa Sub DAS Tapin tersebut sudah cukup representatif mewakili wilayah secara keseluruhan.

\section{Jenis Penelitian}

Jenis penelitian yang akan dilaksanakan ini apabila ditinjau dari tujuannya dapat digolongkan sebagai penelitian pengembangan (research and development study), yaitu tentang Tinjauan Ketersediaan Air Embung Rantau Baru Kabupaten Tapin. Saat ini data-data teknis terkait dengan pengelolaan Sub DAS Tapin masih terpisah dan terdapat pada instansi yang berbeda-beda serta masih bersifat sebagai 
informasi/untuk keperluan pelaporan saja. Untuk itu diperlukan usaha pengumpulan/kompilasi data-data teknis tersebut agar nantinya dapat menjadi data yang berguna dalam hal pengelolaan Sub DAS Tapin. Dalam hai ini, skema tingkat ketersediaan air dapat dijadikan sarana kompilasi data teknis tersebut secara terstruktur, maupun untuk membantu dalam tahap lanjutan analisa sumberdaya air pada embung tersebut.

\section{Alat dan Bahan Penelitian}

Alat-alat yang digunakan dalam penelitian ini secara umum berupa perangkat lunak (software) yang digunakan untuk membantu dalam analisis data, dan metode atau model-model persamaan analisis untuk menyelesaikan permasalahan secara sistematis. Software yang dipergunakan dalam penelitian ini antara lain Microsoft Excel. Metode atau model-model persamaan analisis yang dipergunakan antara lain adalah metode persamaan water balance di Embung Rantau Baru, persamaan penelusuran debit inflow historis dan prosedur pembuatan model keseimbangan neraca air.

Data-data yang diperlukan dalam penelitian ini dibagi menjadi dua, yaitu data sekunder dan data primer. Data sekunder adalah data-data yang didapatkan dari instansi terkait, seperti data klimatologi yang didapatkan dari BMG, data-data bangunan fisik DI didapatkan dari dinas PU, data historis hidrometri dari dinas PU, dan lain-lain. Selain itu untuk mengklarifikasi data-data sekunder juga dilakukan pengecekan langsung ke lapangan agar jelas validitasnya. Data-data primer didapatkan antara lain dari pengujian dan pengamatan secara langsung di lapangan, misalnya pengamatan data pengaruh pasang surut pada lahan sawah; pengujian sumuran untuk mengetahui kondisi aliran air tanah permukaan (subsurface water flow), yang merupakan informasi dasar dalam penentuan salah satu variabel model (debit seepage dan perkolasi); pengamatan muka air di saluran drainase, dan lain-lain. Teknik pengumpulan data dalam penelitian ini dilakukan melalui tiga metoda, yaitu:

1. Pengumpulan data sekunder;

2. Wawancara terhadap stakeholder terkait dan masyarakat di sekitar lokasi penelitian; dan

3. Observasi lapangan.

Kebanyakan data yang digunakan sebagai bahan analisis adalah jenis data sekunder yang diperoleh dari instansi terkait. Data primer yang digunakan adalah berupa hasil wawancara dengan stakeholder terkait dan masyarakat di sekitar lokasi penelitian, serta data observasi gambaran aktual wilayah penelitian yang disajikan dalam bentuk deskripsi wilayah. Jenis dan sumber data sekunder yang digunakan adalah berupa data karakteristik fisik wilayah, meliputi:

1. Peta batas administrasi, peta topografi, peta batas wilayah DAS, peta RTRW, dll.

2. Sumber data: Dinas Pekerjaan Umum Pusat Provinsi Kalimantan Selatan, Dinas Pekerjaan Umum Kota Rantau.

3. Data Klimatologi: BMG Wilayah Kota Banjarbaru.

\section{Lokasi Penelitian}

Embung Rantau Baru terletak di desa Rantau Kiwa Kecamatan Tapin Utara, Kabupaten Tapin Provinsi Kalimantan Selatan. Embung ini dibuat sebagai tempat penampungan air sementara akibat limpasan permukaan (Run Off). Selain itu, embung berada pada Sub Daerah Aliran Sungai (DAS) Tapin yang memiliki potensi pengembangan sumberdaya air yang cukup besar, khususnya untuk lahan rawa. Untuk lebih jelasnya dapat dilihat Gambaran Sungai Tapin pada Gambar 3 dan Kondisi Embung Rantau Baru pada Gambar 4. 


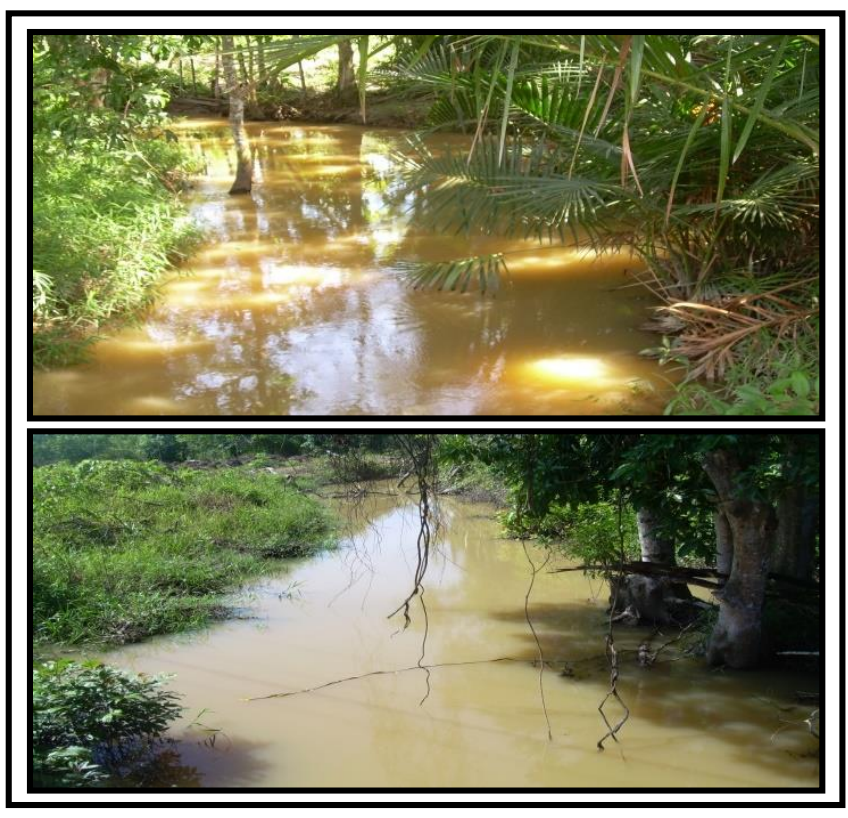

Gambar 3. Gambaran Sungai Salak Sumber: Dokumentasi Pribadi, 2019

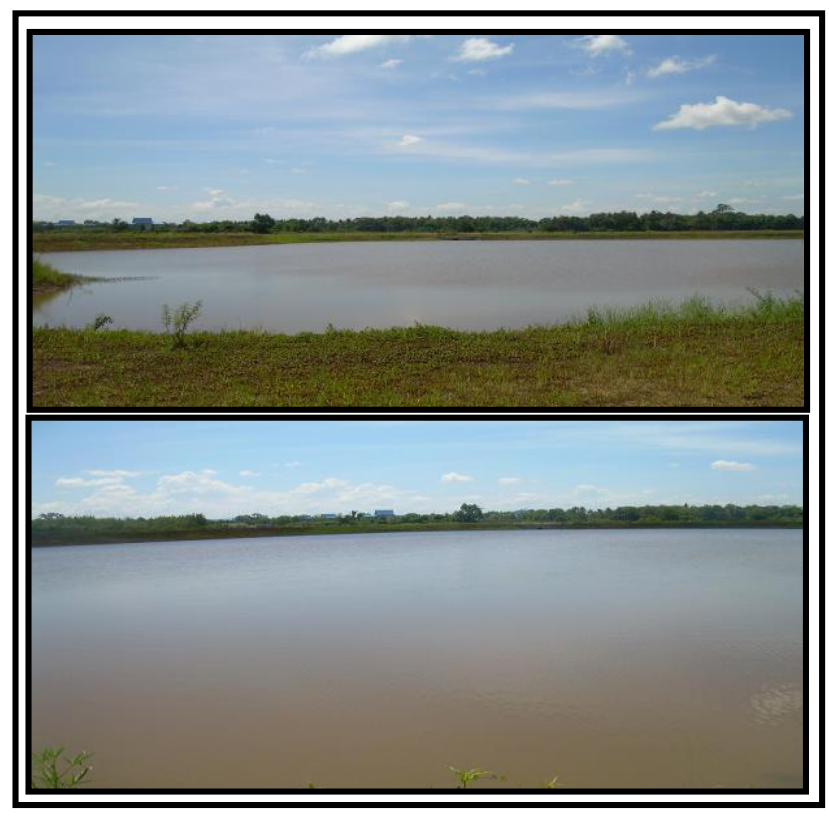

Gambar 4. Kondisi Embung Rantau Baru Sumber: Dokumentasi Pribadi, 2019

\section{Bagan Alir Penelitian}

Bagan alir dari penelitian ini dapat dilihat pada Gambar 5 di bawah ini.

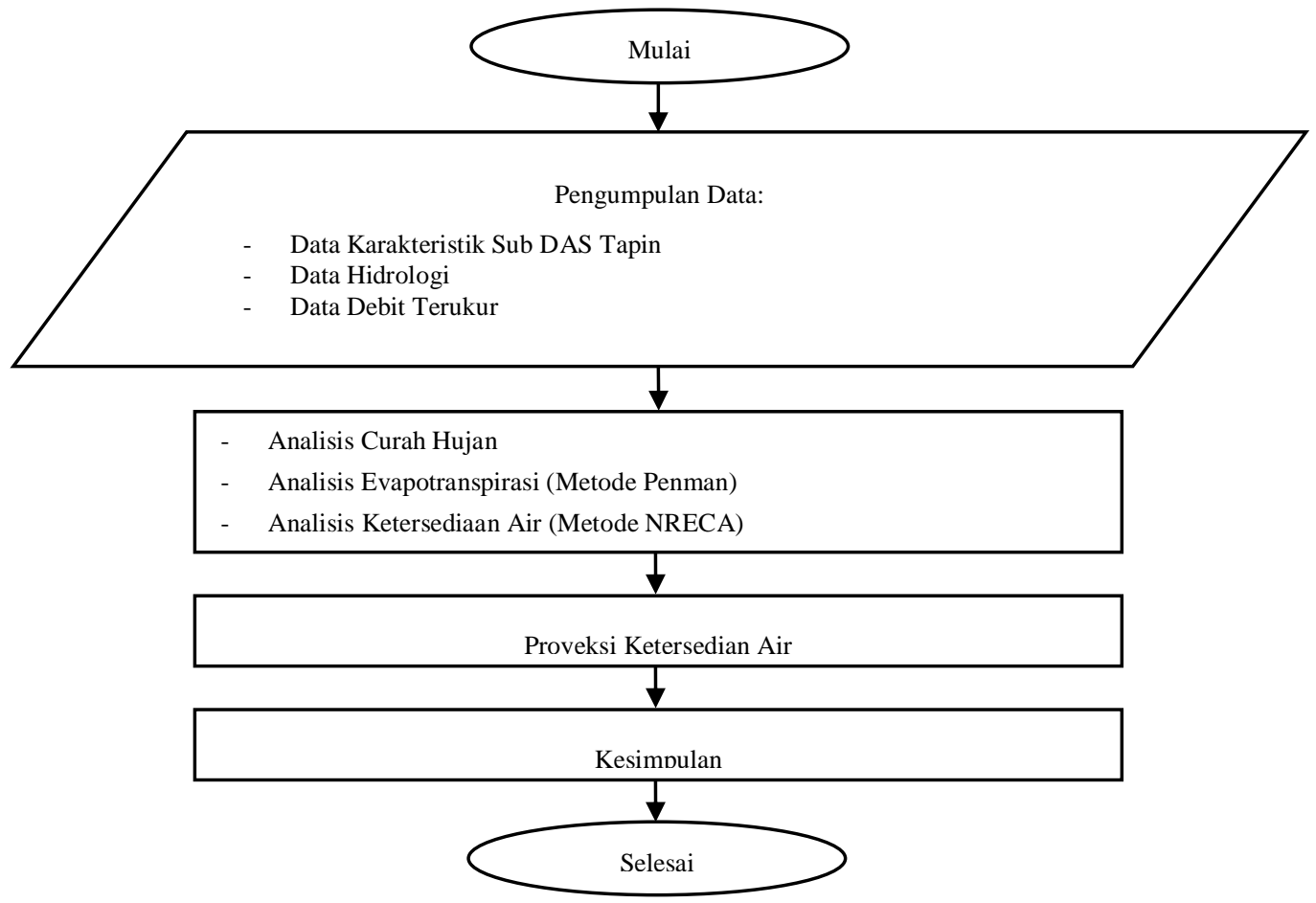

Gambar 5. Bagan Alir Penelitian

Sumber: Analisis, 2019 


\section{HASIL DAN PEMBAHASAN}

\section{Parameter Data Hidrologi}

Parameter data hidrologi dalam penelitian ini antara lain data curah hujan, evaporasi, kelembaban udara, dan kecepatan angin. Prosedur dan hasil perhitungan data hidrologi yang telah di olah tersebut terdapat dalam tabel hasil rata-rata klimatologi Tatakan selama 10 tahun. Data klimatologi bersumber dari stasiun klimatologi Tatakan, Kabupaten Tapin untuk 10 tahun data yaitu: data dari Tahun 2008-2017. Hasil data klimatologi rata-rata selama 10 tahun Tatakan dapat dilihat pada Tabel 1.

Tabel 1. Hasil Rata-Rata Klimatologi Tatakan Selama 10 Tahun

\begin{tabular}{|c|c|c|c|c|c|c|c|}
\hline No. & Bulan & & $\begin{array}{l}\text { Temp } \\
\left({ }^{\circ} \mathrm{C}\right)\end{array}$ & $\mathbf{R H}(\%)$ & $\begin{array}{c}\text { Penguapan } \\
\text { (mm) }\end{array}$ & $\begin{array}{c}\text { Kecepatan } \\
\text { Angin } \\
\text { (Km/hari) }\end{array}$ & $\begin{array}{c}\text { Sinar } \\
\text { Matahari } \\
(\%)\end{array}$ \\
\hline 1 & Januari & 1 & 26,8 & 86,0 & 2,6 & 82,1 & 39,3 \\
\hline 2 & Januari & 2 & 28,0 & 84,6 & 2,8 & 85,4 & 40,4 \\
\hline 3 & Februari & 1 & 26,5 & 84,4 & 2,9 & 89,8 & 47,1 \\
\hline 4 & Februari & 2 & 27,0 & 85,0 & 3,3 & 86,4 & 48,0 \\
\hline 5 & Maret & 1 & 27,0 & 84,3 & 3,1 & 70,2 & 47,9 \\
\hline 6 & Maret & 2 & 27,3 & 85,3 & 2,9 & 66,5 & 53,0 \\
\hline 7 & April & 1 & 29,0 & 84,3 & 3,0 & 67,7 & 53,6 \\
\hline 8 & April & 2 & 28,1 & 84,0 & 3,0 & 67,2 & 56,3 \\
\hline 9 & Mei & 1 & 27,4 & 83,0 & 3,1 & 60,7 & 52,1 \\
\hline 10 & Mei & 2 & 27,4 & 83,6 & 3,4 & 63,9 & 53,9 \\
\hline 11 & Juni & 1 & 27,3 & 82,6 & 3,2 & 65,8 & 62,4 \\
\hline 12 & Juni & 2 & 27,5 & 82,1 & 3,6 & 70,9 & 64,2 \\
\hline 13 & Juli & 1 & 27,3 & 81,3 & 4,0 & 67,8 & 58,4 \\
\hline 14 & Juli & 2 & 27,8 & 80,4 & 5,0 & 78,5 & 77,4 \\
\hline 15 & Agustus & 1 & 27,8 & 78,0 & 5,1 & 81,7 & 76,8 \\
\hline 16 & Agustus & 2 & 27,6 & 78,3 & 5,6 & 84,9 & 75,9 \\
\hline 17 & September & 1 & 28,1 & 79,8 & 5,6 & 103,1 & 70,6 \\
\hline 18 & September & 2 & 27,9 & 79,7 & 5,1 & 92,6 & 65,0 \\
\hline 19 & Oktober & 1 & 27,7 & 81,0 & 5,0 & 87,3 & 64,9 \\
\hline 20 & Oktober & 2 & 27,8 & 81,5 & 4,7 & 91,7 & 56,4 \\
\hline 21 & November & 1 & 27,5 & 82,8 & 3,5 & 79,5 & 50,0 \\
\hline 22 & November & 2 & 25,5 & 83,7 & 3,1 & 72,2 & 49,3 \\
\hline 23 & Desember & 1 & 25,5 & 84,4 & 2,7 & 75,7 & 40,6 \\
\hline 24 & Desember & 2 & 27,0 & 83,7 & 2,5 & 88,4 & 39,5 \\
\hline
\end{tabular}

(Sumber: Analisis, 2019)

\section{Analisis Data Klimatologi dengan Evapotranspirasi Penman}

Analisis Model NRECA memerlukan data evapotranspirasi yang di sini cara perhitungan menggunakan Metode Penman. Metode Penman dalam hitungannya menggunakan data iklim rerata tahunan, prakiraan besarnya evapotranspirasi dengan Metode Penman dianggap mempunyai derajat ketelitian yang cukup 
tinggi dibandingkan dengan metode lainnya. Hasil perhitungan evapotranspirasi dengan Metode Penman disajikan pada Tabel 2.

\section{Analisis Ketersediaan Debit}

Besaran debit diperoleh dari besarnya curah hujan yang jatuh di DAS Sungai Salak, sehingga menghitung debit, data utamanya adalah curah hujan di stasiun pencatat curah hujan, yaitu stasiun Bungur. Hasil perhitungan debit rata-rata Sungai Salak disajikan pada Tabel 3 dan grafik debit rerata bulanan masuk Embung Rantau Baru disajikan pada Gambar 6.

Tabel 2. Hasil Perhitungan Evapotranspirasi Metode Penman

\begin{tabular}{|c|c|c|}
\hline Bulan & Data & Eto $(\mathrm{mm})$ \\
\hline \multirow{2}{*}{ Januari } & $\mathrm{I}$ & 54,32 \\
\hline & II & 60,57 \\
\hline \multirow{2}{*}{ Februari } & I & 59,62 \\
\hline & II & 52,24 \\
\hline \multirow{2}{*}{ Maret } & $\mathrm{I}$ & 59,78 \\
\hline & II & 65,93 \\
\hline \multirow{2}{*}{ April } & I & 61,94 \\
\hline & II & 62,07 \\
\hline \multirow{2}{*}{ Mei } & $\mathrm{I}$ & 55,10 \\
\hline & II & 59,47 \\
\hline \multirow{2}{*}{ Juni } & I & 56,49 \\
\hline & II & 57,75 \\
\hline \multirow{2}{*}{ Juli } & $\mathrm{I}$ & 56,43 \\
\hline & II & 69,24 \\
\hline \multirow[b]{2}{*}{ Agustus } & I & 69,95 \\
\hline & II & 74,12 \\
\hline \multirow{2}{*}{ September } & $\mathrm{I}$ & 72,32 \\
\hline & II & 68,99 \\
\hline \multirow{2}{*}{ Oktober } & I & 69,38 \\
\hline & II & 70,26 \\
\hline \multirow{2}{*}{ Nopember } & I & 60,69 \\
\hline & II & 57,31 \\
\hline \multirow{2}{*}{ Desember } & I & 53,00 \\
\hline & II & 58,82 \\
\hline Eto Tahunan & (mm/tahun) & 1485,78 \\
\hline
\end{tabular}


Tabel 3. Hasil Perhitungan Debit Rata-rata Sungai Salak (mm/detik)

\begin{tabular}{|c|c|c|c|c|c|c|c|c|c|c|c|c|c|}
\hline \multirow{2}{*}{ Tahun } & \multicolumn{12}{|c|}{ Bulan } & \multirow{2}{*}{ Jumlah } \\
\hline & Jan & Peb & Mar & Apr & Mei & Jun & Jul & Agust & Sept & Okt & Nop & Des & \\
\hline 2008 & 0,057 & 0,029 & 0,000 & 0,000 & 0,008 & 0,000 & 0,000 & 0,000 & 0,000 & 0,036 & 0,097 & 0,092 & 0,318 \\
\hline 2009 & 0,231 & 0,095 & 0,046 & 0,044 & 0,000 & 0,000 & 0,000 & 0,000 & 0,000 & 0,022 & 0,275 & 0,722 & 1,435 \\
\hline 2010 & 0,793 & 0,205 & 0,223 & 0,075 & 0,142 & 0,160 & 0,260 & 0,142 & 0,063 & 0,276 & 0,317 & 0,393 & 3,049 \\
\hline 2011 & 0,466 & 0,342 & 0,273 & 0,113 & 0,173 & 0,901 & 0,108 & 0,012 & 0,000 & 0,271 & 0,249 & 0,345 & 3,253 \\
\hline 2012 & 0,301 & 0,097 & 0,251 & 0,154 & 0,060 & 0,047 & 0,000 & 0,000 & 0,012 & 0,051 & 0,224 & 0,309 & 1,505 \\
\hline 2013 & 0,287 & 0,178 & 0,291 & 0,218 & 0,000 & 0,068 & 0,000 & 0,000 & 0,000 & 0,248 & 0,297 & 0,354 & 1,941 \\
\hline 2014 & 0,401 & 0,106 & 0,243 & 0,176 & 0,014 & 0,094 & 0,000 & 0,000 & 0,000 & 0,050 & 0,239 & 0,222 & 1,543 \\
\hline 2015 & 0,341 & 0,321 & 0,197 & 0,113 & 0,000 & 0,000 & 0,000 & 0,000 & 0,029 & 0,029 & 0,088 & 0,295 & 1,413 \\
\hline 2016 & 0,454 & 0,291 & 0,224 & 0,082 & 0,086 & 0,000 & 0,044 & 0,000 & 0,000 & 0,000 & 0,102 & 0,636 & 1,920 \\
\hline 2017 & 0,345 & 0,423 & 0,542 & 0,111 & 0,101 & 0,000 & 0,000 & 0,000 & 0,000 & 0,321 & 0,102 & 0,241 & 2,187 \\
\hline Jumlah & 3,674 & 2,087 & 2,290 & 1,086 & 0,585 & 1,270 & 0,412 & 0,154 & 0,105 & 1,304 & 1,989 & 3,608 & 18,564 \\
\hline Rata-rata & 0,367 & 0,209 & 0,229 & 0,109 & 0,058 & 0,127 & 0,041 & 0,015 & 0,010 & 0,130 & 0,199 & 0,361 & 1,856 \\
\hline
\end{tabular}

(Sumber: Analisis, 2019)

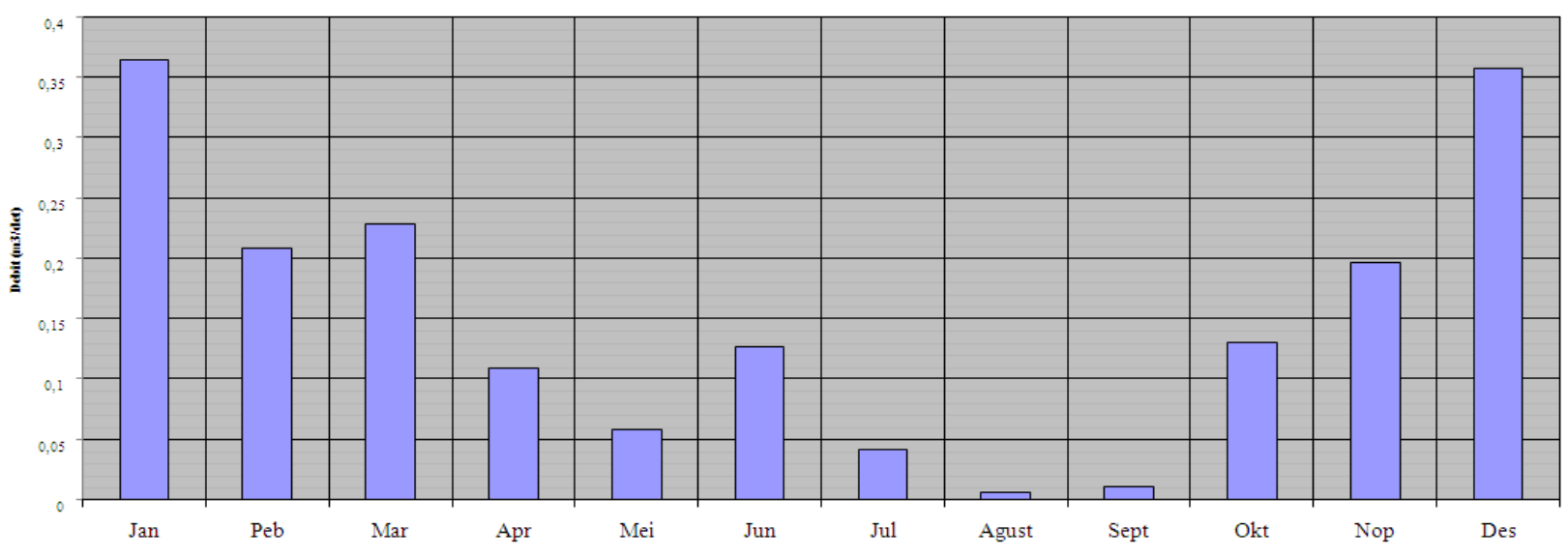

Gambar 6. Grafik Debit Rerata Bulanan Masuk Embung Rantau Baru

Sumber: Analisis, 2019

Dalam analisis ketersediaan air, harus diketahui terlebih dahulu besarnya potensi air dan besarnya penggunaan air yang ada. Potensi air yang dimaksud di sini adalah besarnya debit andalan yang telah direncanakan untuk daerah yang dianalisis. Hasil perhitungan debit andalan (Q80\%) di Sungai Salak disajikan pada Tabel 4. 
Tabel 4. Hasil Perhitungan Debit Andalan Sungai Salak ( $\mathrm{m}^{3} /$ detik)

\begin{tabular}{|c|c|c|}
\hline \multirow{2}{*}{ No } & Bulan & $\begin{array}{c}\text { Debit Andalan }(\mathbf{Q 8 0} \%) \\
\left(\mathbf{m}^{\mathbf{3}} \mathbf{/ d t}\right)\end{array}$ \\
\hline 1 & Januari & 0,287 \\
\hline 2 & Februari & 0,097 \\
\hline 3 & Maret & 0,197 \\
\hline 4 & April & 0,075 \\
\hline 5 & Mei & 0,000 \\
\hline 6 & Juni & 0,000 \\
\hline 7 & Juli & 0,000 \\
\hline 8 & Agustus & 0,000 \\
\hline 9 & September & 0,000 \\
\hline 10 & Oktober & 0,029 \\
\hline 11 & Nopember & 0,102 \\
\hline 12 & Desember & 0,241 \\
\hline
\end{tabular}

\section{PENUTUP}

\section{Kesimpulan}

Berdasarkan hasil analisis di atas, maka dapat diambil kesimpulan bahwa analisis ketersediaan air Embung Rantau Baru dengan menggunakan metode NRECA diperoleh debit andalan (Q80\%) di Sungai Salak paling rendah pada bulan Mei, Juni, Juli, Agustus dan September sebesar 0,000 m3/detik (volume air 0,000 m3) dan paling tinggi 0,287 m3/detik (volume air 0,767 juta m3) pada bulan Januari, sehingga ketersediaan air di Embung Rantau Baru totalnya sebesar 2,712 juta m3/tahun.

\section{Ucapan Terimakasih}

Penulis mengucapkan terimakasih kepada kawan-kawan dan rekan sejawat di Program Studi (S-1) Teknik Sipil, Fakultas Teknik, Universitas Islam Kalimantan Muhammad Arsyad Al Banjari serta semua pihak yang telah banyak membantu kelancaran dan selesainya penelitian ini. 


\section{DAFTAR PUSTAKA}

Anonim, 2006, Laporan Akhir Identifikasi Masalah Pengelolaan Sumber Daya Air di Pulau Jawa, Direktorat Pengairan dan Irigasi, Kementerian Negara Perencanaan Pembangunan Nasional/Badan Perencanaan Pembangunan Nasional, Jakarta.

Anonim, 2007, Rencana Tata Bangunan dan Lingkungan (RTBL) Rantau Baru, Pemerintah Kabupaten Tapin, PT. M. 17 Engineering, Rantau.

Anonim, 2008, Rencana Kawasan Terpadu Kota Rantau Baru, Universitas Lambung Mangkurat Fakultas Teknik, Banjarbaru.

Anonim, 2009, Pedoman Teknis Konservasi Air Melalui Pembangunan Embung/Dam Parit, Direktorat Pengelolaan Air, Direktorat Jenderal Pengelolaan Lahan dan Air, Departemen Pertanian, Jakarta.

Anonim 1, 2018, Kabupaten Tapin, http://www.tapinkab.go.id, Diakses tanggal 26 Juli 2018.

Anonim 2, 2018, Kabupaten Tapin, http://www.wikipedia.co.id/kabupatentapin/, Diakses tanggal 26 Juli 2018.

Anonim 3, 2018, Siklus Hidrologi, http://www.physicalgeography.net/physgeoglos/, Diakses tanggal 11 Agustus 2018. 